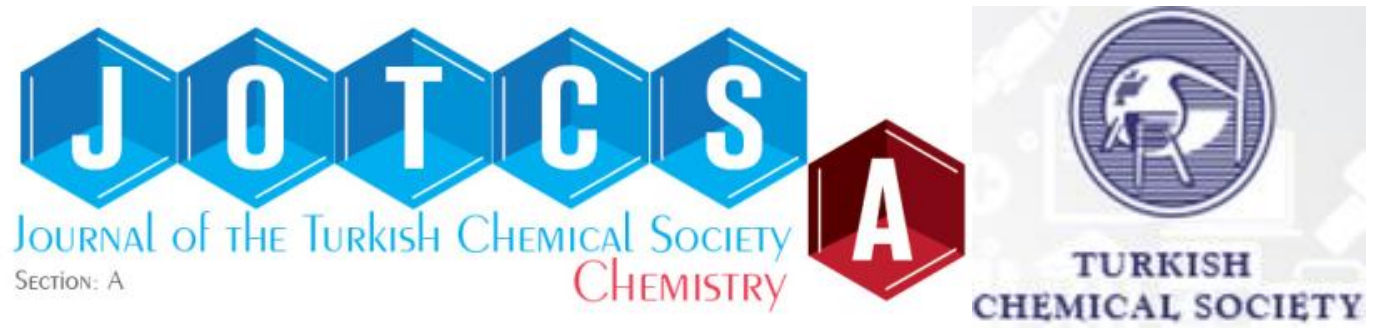

\title{
Thermally Stable Rice Husk Microcrystalline Cellulose as Adsorbent in PTLC Plates
}

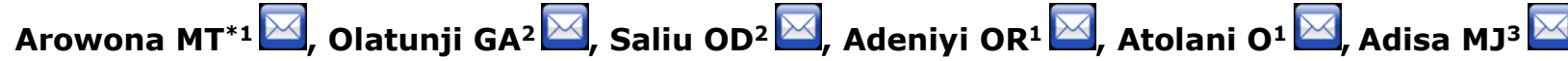 \\ ${ }^{1}$ Department of Chemistry, University of Ilorin, Ilorin, P.M.B. 1515, Nigeria. \\ ${ }^{2}$ Department of Industrial Chemistry, University of Ilorin, Ilorin, P.M.B. 1515, Nigeria. \\ ${ }^{3}$ Department of Chemistry, Ibrahim Badamasi Babangida University, P.M.B. 11, Lapai, Niger State.
}

Abstract: Microcrystalline cellulose (MCC) was prepared from rice husk by subjecting it to alkaline pretreatment, delignification, bleaching, and hydrolytic operations. MCC was also prepared from cotton wool and used as a reference because of its high cellulose content to estimate a relative yield and quality of the MCC produced from rice husk. The characteristic morphological feature was established by scanning electron micrograph (SEM) and the crystallinity of the Rice husk Microcystalline cellulose was further confirmed using the X-RD technique; the functional group was confirmed by the Fourier transform infrared (FTIR) spectroscopic method with characteristic absorption bands of ; $-\mathrm{OH}$ stretching at $3416 \mathrm{~cm}^{-1} ; \mathrm{C}-\mathrm{H}$ stretching at $2918 \mathrm{~cm}^{-1}$; $\mathrm{OH}$ bending at $1377 \mathrm{~cm}^{-1} ;, 1159 \mathrm{~cm}^{-1}$; and C-O-C pyranose ring skeletal vibrations at $1026-1033 \mathrm{~cm}^{-1}$, and the thermal stability was determined from thermogravimetric analysis (TGA). The characterized MCC of rice husk was applied as a stationary phase in Preparative Thin Layer Chromatography gave good separation (PTLC).

Keywords: Rice Husk, Microcrystalline cellulose, Chromatography, Scanning Electron Micrography.

Submitted: July 10, 2017. Accepted: September 24, 2018.

Cite this: Arowona M, Olatunji G, Saliu O, Adeniyi O, Atolani O, Adisa M. Thermally Stable Rice Husk Microcrystalline Cellulose as Adsorbent in PTLC Plates. JOTCSA. 2018;5(3):1177-84.

DOI: $\underline{\text { http://dx.doi.org/10.18596/jotcsa.327665. }}$

*Corresponding author. E-mail: temitopemariam11@yahoo.com.

\section{INTRODUCTION}

Rice which is one of the most generally consumed cereal crop in the world has its husk usually discarded as raw biomass material. This raw biomass material which forms waste can be well harnessed, processed or manipulated into other forms of research materials and industrial raw materials that can be further employed in the fabrication of products with high market, economical, industrial and usage values. This rice husk can undergo combustion to produce ash which is rich in silica which can be applied singly or as composite for adsorption, water treatment, degradation of persistent contaminants and pollutants, etc. Another way to use rice bran involves the exploitation of its cellulose content which therefore makes the use of rice husk as a primary source for producing cellulose fibres and microcrystals promising.

Recently, lignocellulosic biomass like the rice husk has become the most widely used organic biomaterial in the world, with a worldwide consumption that is even higher than steel, coal or sugar (1). Pretreatment is a crucial process step for the biochemical conversion of lignocellulosic biomass and it is important to remove lignin, hemicelluloses, holocelluloses, increase cellulose quality and improve the porosity of the materials (2). The preparation of microcrystalline cellulose from readily available agricultural residues such as 
rice husk will therefore, have good impact on the economy through the conversion of waste to wealth and consequently reduce the cost of the purchase of commercially produced modified microcrystalline cellulose.

Microcrystalline cellulose is a purified partially depolymerized non-fibrous form of cellulose that occurs as a white, odorless, tasteless, crystalline powder composed of porous particles. Microcrystaline cellulose (MCC) produced from a naturally occurring substance (cellulose) has proven to be stable, safe and physiologically inert and has revolutionized tableting. Microcrystalline cellulose is one of the few materials used in tableting due to its potential to produce hard tablet that also disintegrate readily in bodies due to swelling of the MCC particles and collapse of the intermolecular bonding forces holding the molecules together (3). Currently, MCC is used in various fields such as pharmacy, cosmetics, food industries, and plastics industries. In the powder form, it is used as a filler and binder in medical tablets and food tablets for dietary purposes. In the gel form, MCC is used as viscosity regulator, a suspending agent, emulsifier in different pastes, creams, etc. (4).

Success of the separation of a complex mixture by TLC and PTLC greatly depends on the choice of stationary phase. Adsorbents generally used include silica gel, alumina, cellulose, polyamide, polymeric ion exchange, impregnated silica gel and chiral phases. While all these adsorbent are in current use, silica gel is by far the most widely used adsorbent followed by alumina. For effective separations, most stationary phases were impregnated with other materials such as ion exchangers, metal ions, chiral selectors, cellulose, etc in ranging proportions. The aim of this work is to obtain microcrystalline cellulose that can be thermally stable and suitable for use as an alternative adsorbent in preparative thin layer chromatography.

\section{MATERIALS AND METHOD}

\section{Materials}

Dried rice bran was collected from local rice mill at Ipata market, Ilorin, Kwara State,North Central region of Nigeria. Cotton wool was purchased commercially. All reagents and solvents used which include sodium chlorite, acetic acid, potassium hydroxide, sodium hypochlorite, sulfuric acid, silica gel, and ethanol were obtained from Sigma Aldrich, USA.

\section{Preparation of crude cellulose}

The cellulose was prepared using the procedure described by Liu et al. (5) with slight modifications. $100 \mathrm{~g}$ of the sample was weighed and transferred into a $1000 \mathrm{~mL}$ beaker containing a solution of 100 g sodium chlorite adjusted to a pH 4.0 using $10 \%$ acetic acid at $75^{\circ} \mathrm{C}$ for $1 \mathrm{~h}$ for delignification. Then, $100 \mathrm{~g}$ of sodium chlorite was added while stirring continuously for another $1 \mathrm{~h}$ at same temperature to further delignify the biomass material. The residue was washed with distilled water and ethanol until its $\mathrm{pH}$ became neutral, the resulting solution was filtered, the residue was thereafter washed and dried in an oven at $60^{\circ} \mathrm{C}$ for $5 \mathrm{~h}$. Afterwards, the dried residue was treated with $10 \%$ potassium hydroxide for $6 \mathrm{~h}$ to complete the delignification process. The cellulose gotten was washed with distilled water and ethanol and dried for $3 \mathrm{~h}$ at 60 ${ }^{\circ} \mathrm{C}$. Thereafter, it was treated with sodium hypochlorite, washed with distilled water and ethanol and dried in an oven at $60^{\circ} \mathrm{C}$ for $3 \mathrm{~h}$. The cellulose was blended to obtain a smooth powdery texture, weighed, stored in sample bottles and kept in a cool dry place until further analysis.

\section{Preparation of Microcrystalline Cellulose}

The delignified pre-weighed cellulose was transferred into a quick fit flask and $500 \mathrm{~mL}$ of 2 $\mathrm{M} \mathrm{H}_{2} \mathrm{SO}_{4}$ was added and then refluxed at $60{ }^{\circ} \mathrm{C}$ for $3 \mathrm{~h}$. The microcrystalline cellulose obtained was then washed with distilled water and ethanol, dried in the oven, blended, weighed and then stored. Also, MCC from cotton wool was prepared using the same procedure.

\section{Characterization}

Surface morphology of the cellulose fibers and metal oxides composites was investigated using Phenom ProX Scanning Electron Microscopy, USA. Before the analysis, the composites were sputtered with thin gold layer to avoid electrostatic charging during examination. The micrographs with a magnification of 50,000 times were obtained by back scattered electron detector (BSE) in order to register both topography and compositional contrast. X-ray diffraction pattern of the sample was investigated using $X$-ray diffraction (D8 Advance, Bruker, Germany) equipped with $\mathrm{Cu} \mathrm{Ka}$ radiation in the $2 \theta$ range $5^{\circ}-60^{\circ}$ with step size of $0.03^{\circ}$ was used under the operational conditions of $40 \mathrm{kV}$ and $40 \mathrm{~mA}$. All of the assays were performed with a scan rate of $12 \% \mathrm{~min}$ and wavelength of 1.540562. TGA measurements were performed using (STA449 F3, Netzsch, Germany) under a nitrogen atmosphere $(40 \mathrm{~mL} / \mathrm{min})$, and the samples were heated at $10^{\circ} \mathrm{C} / \mathrm{min}$ from $50^{\circ} \mathrm{C}$ to $850^{\circ} \mathrm{C}$. The weight loss (\%) was evaluated by measuring the residual weight at $8500^{\circ} \mathrm{C}$. TGA and derivative thermo-gravimetric analysis (DTG) data were obtained.

The functional groups in the crude and microcrystalline cellulose prepared were analyzed by using the Agilent Cary 630 FTIR 
spectrophotometer, USA, in the range of $400-4000$ $\mathrm{cm}^{-1}$ in transmittance mode.

\section{Application of Microcrystalline Cellulose as} Adsorbent on Chromatographic Plates

Five grams of MCC prepared from rice bran were weighed and mixed with $50 \mathrm{~g}$ of silica gel (ratio $1: 10$ ) and $100 \mathrm{~mL}$ water was used to coat on a plate $20 \times 20 \mathrm{~cm}$. The ethanolic extract of the leaves of Momordica charantia was spotted on the plate and developed in n-hexane and dichloromethane in the ratio $2: 1$. The separation of the crude extract into different components was observed.

\section{RESULTS AND DISCUSSION}

\section{Isolation and preparation of microcrystalline} cellulose:

The microcrystalline cellulose (MCC) obtained from both rice husk and cotton wool, as well as the crude cellulose obtained from rice husk was all white and powdery. The crude cellulose obtained from rice husk was white while the MCC obtained from both the rice husk and cotton wool was white and powdery (Figure $\mathbf{1} \mathbf{a}, \mathbf{b}, \mathbf{c}, \mathbf{d}, \mathbf{e}$ ). The percentage yield (Table 1 ) of MCC obtained indicated that the rice husk crude cellulose produced more MCC than the cotton wool cellulose.

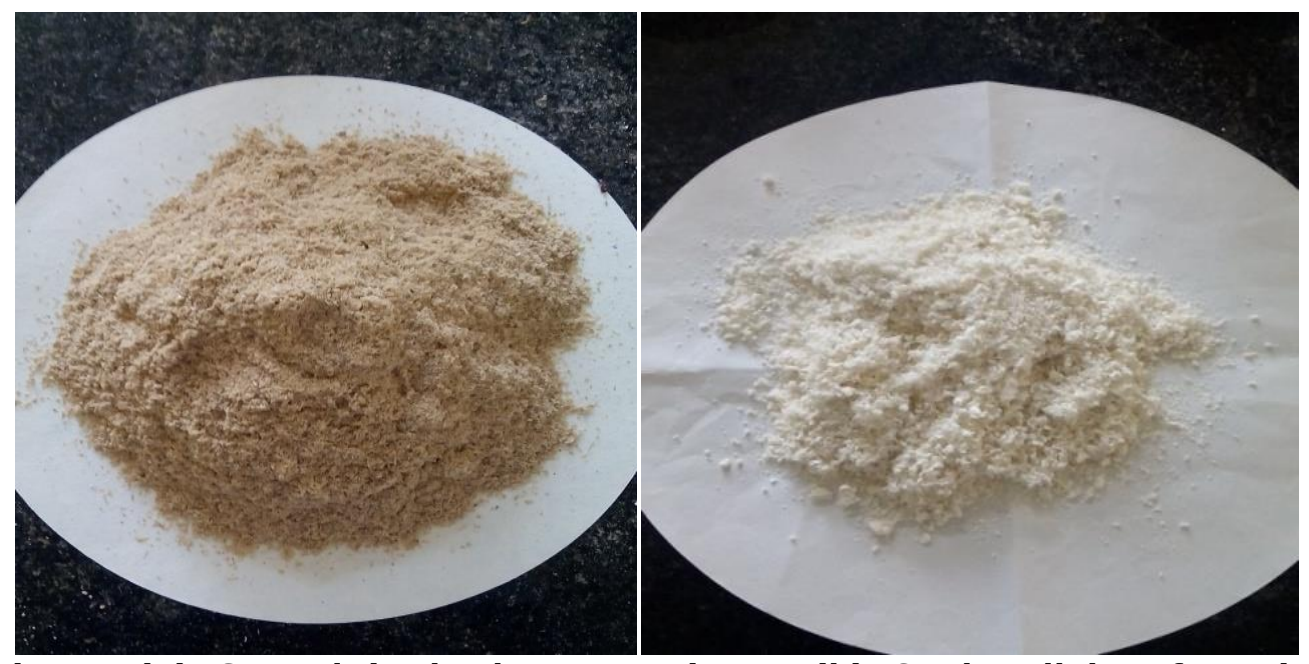

Figure 1(a): Ground rice husk

Figure 1(b): Crude cellulose from rice husk

Figure 1(c):Microcrystalline cellulose from rice husk 

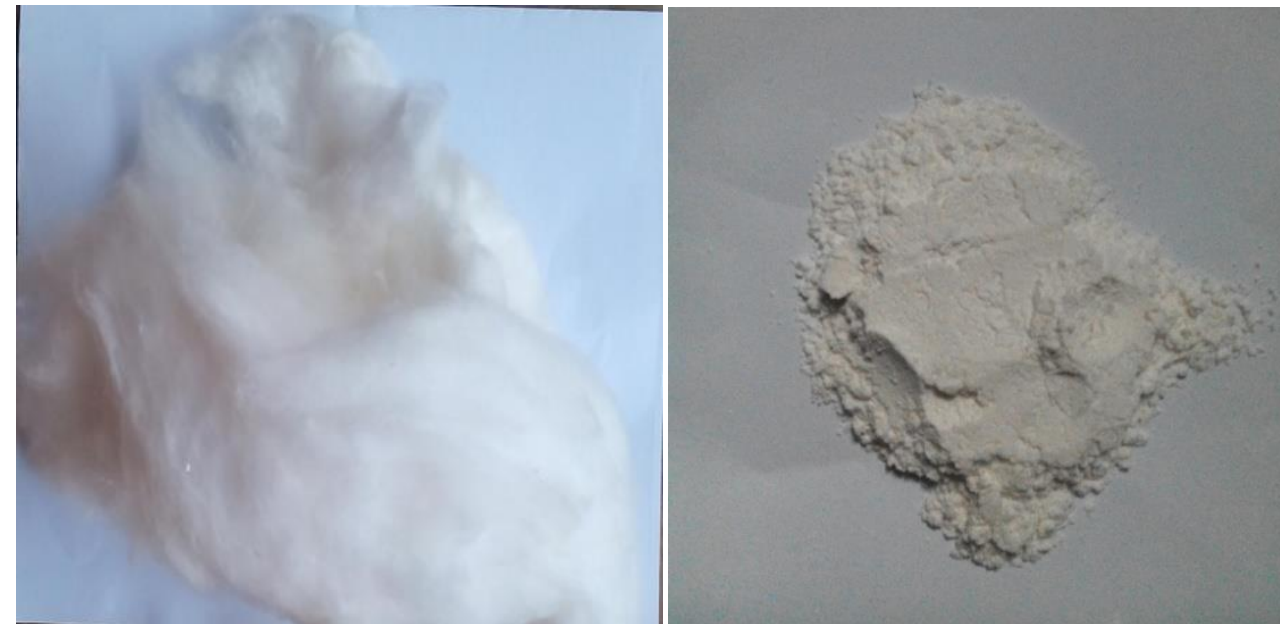

Figure 1(d): Cotton wool

Figure 1(e): Microcrystalline cellulose from cotton wool

Table 1: Percentage Yield of Microcrystalline Cellulose from Rice Husks and Cotton Wool.

\begin{tabular}{lll}
\hline Masses and \% Yield & Rice Husk & Cotton Wool \\
\hline Initial Mass $(\mathrm{g})$ & 20.84 & 30.00 \\
Final Mass $(\mathrm{g})$ & 20.33 & 26.10 \\
$\%$ Yield & $97.55 \%$ & $87.00 \%$ \\
\hline
\end{tabular}

\section{FOURIER TRANSFORM INFRARED (FT-IR) Analysis}

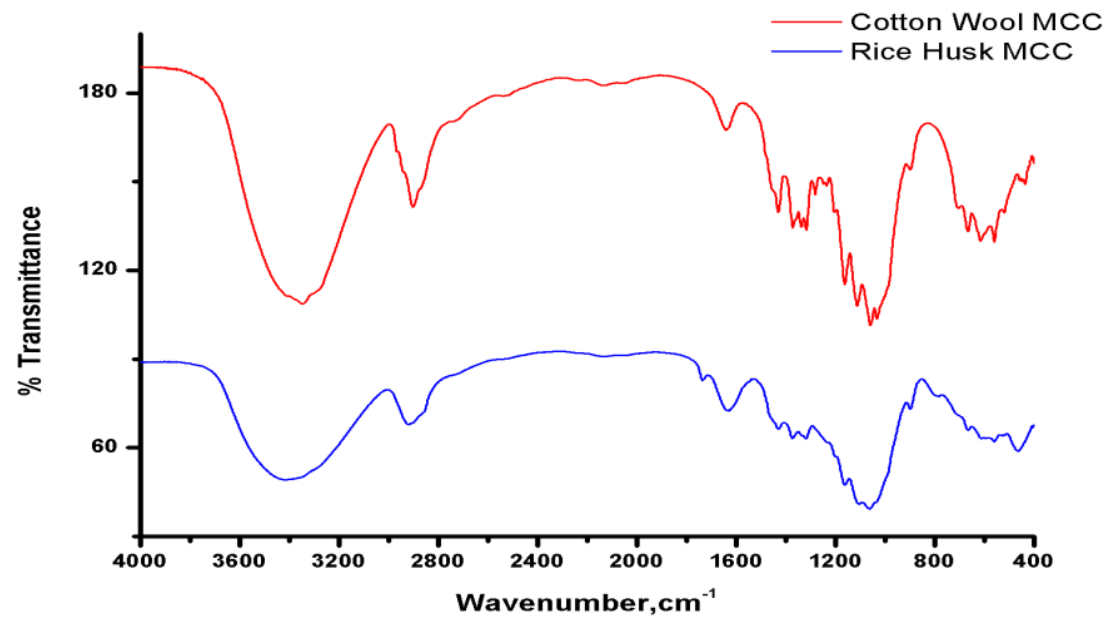

Figure 2: FT-IR Spectrum of Cotton and Rice Husk MCC.

The FTIR spectra in red and blue colors revealed the important absorption bands for the cotton wool and rice husk MCC respectively. This showed similarity with the important peaks on crude cellulose from other source (sugarcane bagasse) reported in literature by Liu et al., (5). The absorption bands and their assignments are: $3416 \mathrm{~cm}^{-1}$; -OH characteristic absorptions, 2918 $\mathrm{cm}^{-1}$; C-H stretching, $1629 \mathrm{~cm}^{-1}$; bending mode of absorbed water, $1377 \mathrm{~cm}^{-1}$; -OH bending, 1159 $\mathrm{cm}^{-1}$; -C-O stretching in acetyl group, 1026-1033 $\mathrm{cm}^{-1}$; C-O-C pyranose ring skeletal vibrations, (6). Oxidation and sulfonation signals were seen at 1736 and $2131 \mathrm{~cm}^{-1}$ as a result of the sulfuric acid treatment for microcrystalline cellulose generation. Cotton wool is $99 \%$ pure cellulose, therefore similarity in absorption for both spectra revealed the successful isolation and purification of cellulose from rice husk.

\section{Morphological Investigation of the Microcrystalline Cellulose}

Scanning electron micrography (SEM): The Scanning Electron Micrographs (SEM) for the MCC of rice husks and cotton wool are as shown in Figure 3 ( $a$ and $b$ ). This was used to analyze the morphology of the microcrystalline celluloses from rice husk and MCC from cotton wool. 


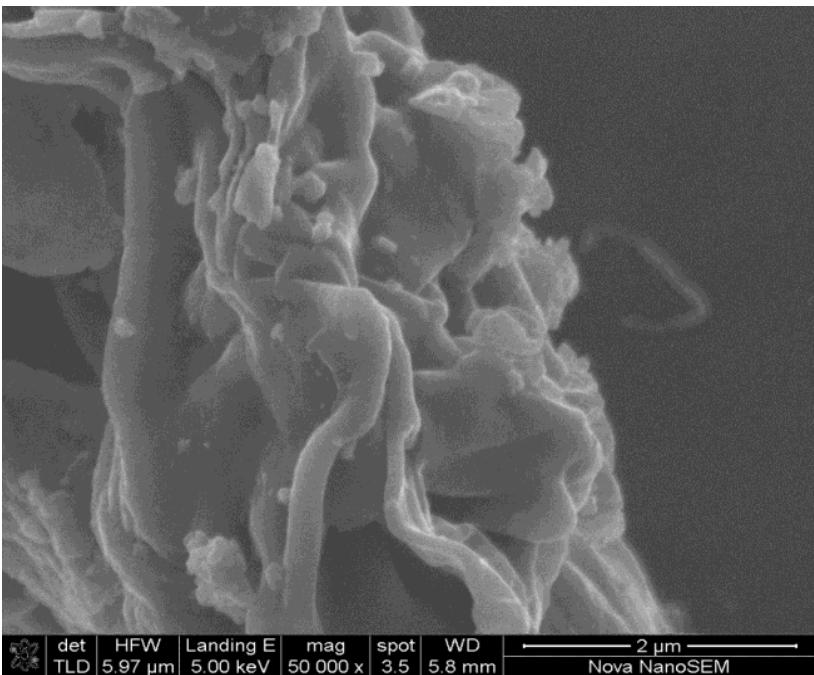

Figure 3 (a): SEM of Microcrystalline Cellulose from rice husk

Comparatively, the SEM of the microcrystalline cellulose from both samples (cotton and rice husk) show non- uniformly dense microcrystalline particles thereby forming microcrystals from the overall view. The MCC are irregularly packed and sponge-like. The high level of aggregation and

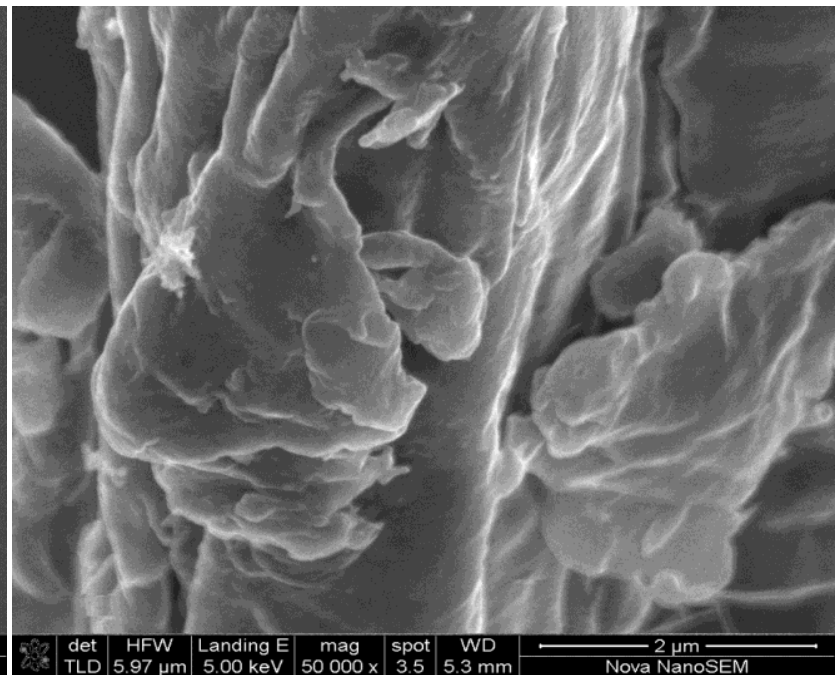

Figure 3 (b): SEM of Microcrystalline Cellulose from cotton wool

agglomeration was evident due to a large number of fiber bundles. Since the rice husk MCC also displayed some level of aggregation like the cotton wool MCC, it is assumed to possess similar morphological properties which resemble that of cotton wool.

\section{X-RAY DIFFRACTION PATTERN (XRD)}

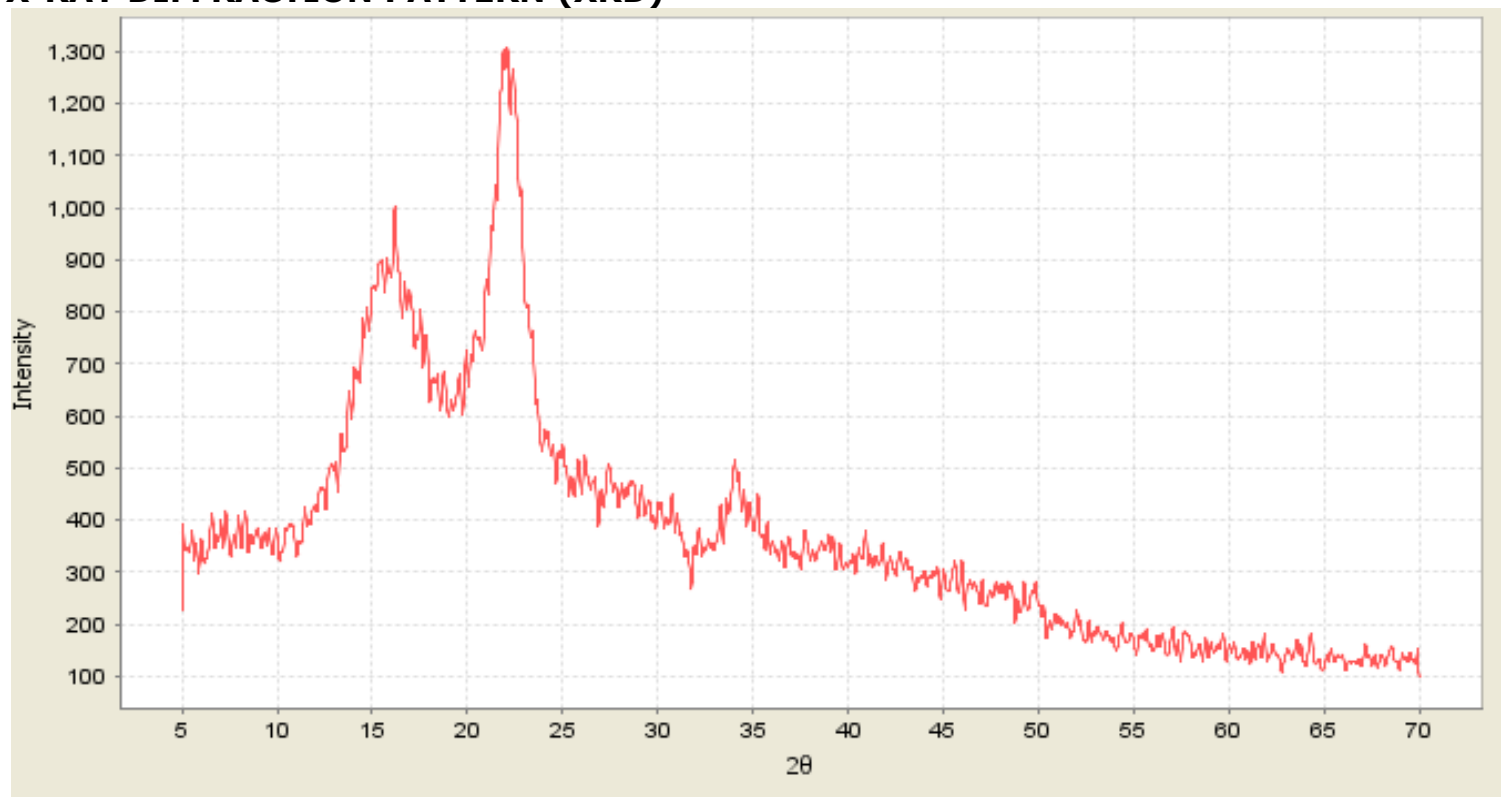

Figure 4: Diffractogram of Rice Husk MCC.

X-ray diffraction (XRD) was carried out to study the crystallinity of the MCC of rice husk. In the X-ray patterns, three main reflections at $2 \theta=14.70^{\circ}$, $22.09^{\circ}$ and $34.24^{\circ}$ were observed for the sample, indicating that the rice husk microcrystalline cellulose and were cellulose I type (7). Furthermore, the similar patterns of $X$-ray diffraction of standard microcrystalline cellulose reported in literature by (8) demonstrated that hydrolysis did not change the cellulose structure of the rice husk MCC, which was in accordance with the results of FT-IR. The crystallinity index was $67 \%$.

The presence of noise in the $X$-ray micrograph might be due to the presence of some residual amorphous cellulose in the sample. 


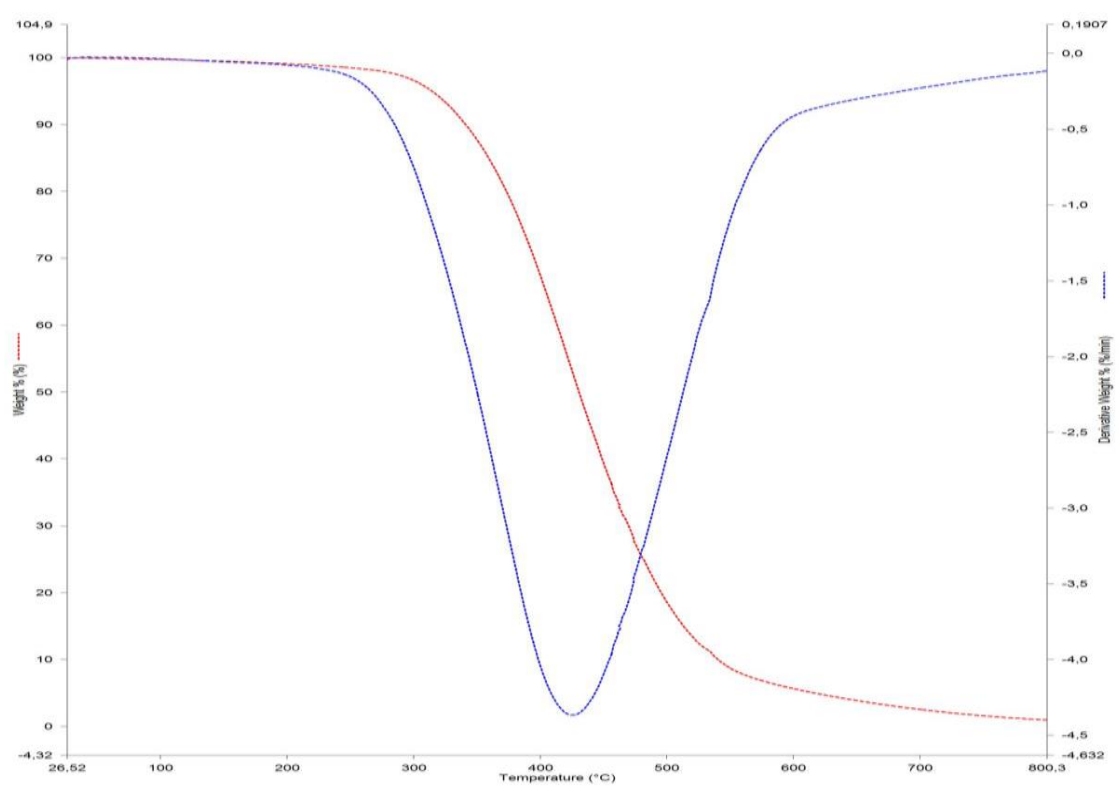

Figure 5: TGA analysis of the sample.

The thermogravimetric analysis (TGA) curve revealed a single step thermal degradation of the microcrystalline cellulose from 360 to $460{ }^{\circ} \mathrm{C}$ with $87 \%$ weight loss. This single step thermal degradation profile displayed by this microcrystalline cellulose confirmed the absence of impurities, hemicelluloses, lignin, and any form of attached water within its internal pores. The microcrystalline cellulose is a thermally stable one; and this is further established by the result of the differential thermogravimetric analysis (DTGA) which revealed that the $T_{\max }$ (the temperature at which maximum weight loss occurs) which occurred at $410{ }^{\circ} \mathrm{C}$ is high and make the MCC a suitable material as adsorbent even in preparative thin layer chromatographic applications.

\section{Use of microcrystalline cellulose as adsorbent}

The absence of pores in the MCC after hydrolysis at a concentration less than $50 \%\left(2 \mathrm{M} \mathrm{H}_{2} \mathrm{SO}_{4}\right)$ of the acid shows that the MCC of rice husk is a suitable stationary phase that will permit easy flow of sample mixture and will not in any way affect the movement of the solute by adsorbing the sample and reacting with it thereby interfering with the elution process on the PTLC plate. The crude extract applied on the PTLC plates were clearly separated into different components after development in appropriate solvents. This result showed that the MCC cellulose obtained from rice husk which was meant to be a waste product from the local rice mill could be converted into useful laboratory material and therefore, serves as an alternative adsorbent.

\section{CONCLUSIONS}

Purification of cellulose was performed using chemical pretreatments involving alkali and bleaching treatments. The MCC were successfully extracted from the purification of rice husk and cotton wool cellulose using an acid hydrolysis treatment. The morphology of the MCC confirmed its suitability for use as stationary phase in PTLC. The percentage yield of the rice husk and cotton wool MCC was determined and gotten to be $97.55 \%$ and $87 \%$ respectively. From the results, it is visible that high percentages of MCC can be gotten from rice husk which is an agricultural residue of little significance in our society today. Instead of disposal of these residues, more MCC can be prepared from them thereby harnessing the potentials embedded in such residues. Since it is suitable as stationary phase in chromatography, it reduces the cost of purchasing commercial stationary phases such as silica gel or alumina. Consequently, the economy of our society in general is enhanced.

\section{REFERENCES}

1. Sanchez OJ, Cardona CA. Trends in biotechnological production of fuel ethanol from different feedstocks. Bioresource technology. 2008;99(13):5270-5295.

2. Sun Y, Cheng J. Hydrolysis of lignocellulosic materials for ethanol production: a review. Bioresource technology. 2002;83(1):1-11.

3. Ejikeme PM. Investigation of the physicochemical properties of microcrystalline 
cellulose from agricultural wastes I: Orange mesocarp. Cellulose. 2008;15(1):141-147.

4. Laka M, Chernyavskaya S. Obtaining of microcrystalline cellulose from softwood and hardwood pulp. BioResources. 2007;2(4):583589.

5. Liu C-F, Sun R-C, Zhang A-P, Qin $M-H$, Ren J-L, Wang X-A. Preparation and characterization of phthalated cellulose derivatives in roomtemperature ionic liquid without catalysts. Journal of agricultural and food chemistry. 2007;55(6):2399-2406.

6. Liu C, Sun R, Zhang A, Ren J. Preparation of sugarcane bagasse cellulosic phthalate using an ionic liquid as reaction medium. Carbohydrate Polymers. 2007;68(1):17-25.

7. Zhao $T$, Chen $Z$, Lin $X$, Ren Z, Li B, Zhang $Y$. Preparation and characterization of microcrystalline cellulose (MCC) from tea waste. Carbohydrate polymers. 2018;184:164-170.

8. Kharismi RRAY, Sutriyo HS. Preparation and Characterization of Microcrystalline Cellulose Produced from Betung Bamboo (Dendrocalamus asper) through Acid Hydrolysis. Journal of Young Pharmacists. 2018;10(2):S79. 
Arowona MT et al. JOTCSA. 2018; 5(3): 1177-1184. 